\title{
O futuro da Amazônia diante da crise cosmoteândrica: a busca por uma espiritualidade que integre todas as dimensões da realidade
}

\author{
The future of the Amazon in the face of the \\ cosmotheanthic crisis: searching for a spirituality that \\ integrates everything as dimensions of reality
}

Francilaide de Queiroz Ronsi

\section{Resumo}

Pensar no futuro da Amazônia não é apenas um movimento ad extra, mas é, também, ad intra, pois não se trata apenas de uma reflexão sobre algo fora de nós, mas sobre algo que constitui a nossa própria realidade. A partir do que significa a missão da Igreja no mundo, entendemos que os cristãos são provocados e convocados a assumirem o que é de mais essencial em sua experiência de fé no compromisso com a evangelização. Tendo em vista que evangelizar significa tornar o Reino de Deus presente nos mais diversos contextos, torna-se prioridade entender a realidade a sua volta. Dessa forma, partimos do princípio de que estamos enfrentando uma crise cosmoteândrica, que atinge profundamente a Amazônia e a todos nós, e do que significa evangelizar para os cristãos. A nossa reflexão nos leva a propor, com a colaboração do místico e teólogo Raimon Panikkar e do Papa Francisco, uma espiritualidade que integre todas as dimensões que constituem a realidade: o divino, o humano e o cosmos. E, por conseguinte, que seja restaurada a responsabilidade do ser humano diante de Deus no cuidado e preservação da natureza, reconciliando-se com toda a criação.

Palavras-chave: Amazônia. Igreja. Missão. Experiência. Reconciliação. 


\begin{abstract}
Thinking about the future of the Amazon is not just an ad extra movement, but it is also ad intra, as it is not just a reflection on something outside of us, but on something that constitutes our own reality. Based on what the Church's mission in the world means, we understand that Christians are provoked and called upon to take on what is most essential in their experience of faith and on the commitment to evangelization. Keeping in mind that evangelizing means to make the Kingdom of God present in the most diverse contexts, it is a priority to understand the reality around us. Therefore, assuming that we are facing a cosmoteandric crisis which deeply affects the Amazon and all of us, and what it means to evangelize for Christians. Our reflection leads us to propose with the collaboration of the mystic and theologian Raimon Panikkar and Pope Francis, a spirituality that integrates all the dimensions that constitute reality: the divine, the humankind and the cosmos. And that the responsibility of human beings be restored towards God in the caretaking and preservation of nature, reconciling with all creation.
\end{abstract}

Keywords: Amazon. Church. Mission. Experience. Reconciliation

\title{
Introdução
}

Queremos iniciar a nossa reflexão lembrando que os cristãos têm como missão tornar o Reino de Deus presente no mundo por meio de sua evangelização, que não acontece sem que seja impulsionada pela experiência de profundo encontro com Jesus Cristo. E, nesse sentido, o seu amadurecimento se dá à medida que se entrega a essa experiência para dar vida aos demais. Por isso, é-lhe exigido entender a realidade a sua volta tendo presente "as alegrias e as esperanças, as tristezas e as angústias dos homens de hoje, sobretudo dos pobres e de todos aqueles que sofrem", pois estas são "as alegrias e as esperanças, as tristezas e as angústias dos discípulos de Cristo; e não há realidade alguma verdadeiramente humana que não encontre eco em seu coração".

Dessa forma, segundo o Papa Francisco, é preciso promover uma solidariedade que permita que todos os povos sejam sujeitos de seu destino. ${ }^{2}$

\footnotetext{
${ }^{1}$ GS 1.

${ }^{2}$ EG 191.
} 
Que os cristãos assumam como um imperativo para a sua missão o cuidado e a atenção para com os mais necessitados, sentindo na sua própria carne o sofrimento alheio, ${ }^{3}$ pois é tarefa da evangelização a promoção integral de todo ser humano. Nesse sentido, não podem estar alheias à sua missão as desigualdades sociais, a pobreza, a crise ambiental e tudo mais que é consequência do egoísmo desmedido de muitas lideranças políticas, empresariais e de outros setores que colaboram para que essa realidade atinja milhões de pessoas em todas as partes do mundo.

Veremos, então, que não nos é possível pensar em desenvolvimento econômico, social e humano independentes das questões ecológicas. Tornase cada vez mais urgente a busca por um desenvolvimento sustentável que privilegie o equilíbrio entre o econômico, o tecnológico, o cuidado e a preservação da natureza para a promoção e a defesa da dignidade do ser humano. Confirma-se cada vez mais a compreensão de que o ser humano pertence a um todo que é complexo, bem articulado e independente.

Nesse sentido, voltar o olhar para a Amazônia é, ao mesmo tempo, estar aberto para compreender e acolher a sua realidade territorial rica em beleza natural, em suas matas, rios e florestas, e rica no esplendor de sua beleza humana, que é multicultural, multirreligiosa e multirracial. ${ }^{4}$ É desenvolver, mediante toda a realidade que envolve o território Pan-Amazônico, ${ }^{5}$ uma espiritualidade que integre todas as dimensões da Realidade. Que seja capaz de escutar os clamores dos povos e da natureza ameaçados pela cobiça política e econômica. Nessa esperança, o Papa Francisco, em 15 de outubro de 2017, anunciou que seria realizada uma Assembleia Especial do Sínodo dos Bispos para a Amazônia, com o tema "Novos caminhos para a Igreja e para a ecologia integral", que se realizou em outubro de 2019.

Por conseguinte, na elaboração de nossa reflexão contaremos com as contribuições do Papa Francisco, por meio de sua Carta Encíclica Laudato Si’ e das Exortações Apostólicas Evangelii Gaudium e Querida Amazônia

\footnotetext{
${ }^{3}$ EG 193.

${ }^{4}$ A nossa reflexão não pretende desenvolver um estudo sobre a riqueza religiosa, étnica e cultural do território Pan-Amazônico em suas especificidades. Por essa razão, indicamos os estudos realizados pela Rede Eclesial Pan-Amazônica (http://repam.org.br) e as teses: PACHECO, A. S., En el corazón de la Amazonía; CASTRO, R. G., Redimindo Masculinidades.

${ }^{5}$ A Pan-Amazônia envolve os países que têm a floresta amazônica em seu território, são eles: Colômbia, Peru, Venezuela, Equador, Bolívia, as Guianas e o Suriname, além do Brasil. O movimento social se apropriou desse conceito para representar as causas de luta dos povos originários desse território.
} 
(Exortação Pós-Sínodo da Amazônia), e do místico e teólogo Raimon Panikkar, com o núcleo central do seu pensamento, o que ele denominou intuição cosmoteândrica. Veremos que essa intuição não é uma ideia ou um aprendizado intelectual, mas uma experiência (uma experiência mística). Não é uma compreensão analítica. "A intuição cosmoteândrica não é uma divisão tripartida entre os seres, senão um olhar para o centro tridimensional de tudo o que é, enquanto é". ${ }^{6}$ Em outras palavras, o divino, o humano e o cósmico são três dimensões de toda a Realidade; Deus, Homem e Mundo são suas "partes" constitutivas.

A partir de sua intuição cosmoteândrica, conheceremos o termo ecosofia, que pretende ir além do saber científico de que trata a ecologia. Sem deixar o que essa ciência nos propõe, ele avança sugerindo uma mudança na relação do ser humano com a terra. Essa palavra sugere o reconhecimento de uma sabedoria presente na nossa oikos, que consta nas cosmovisões de muitos povos, e que revelam novos paradigmas de convivência com a terra.

Por conseguinte, procuraremos desenvolver um caminho para uma espiritualidade que consiga responder aos desafios que ameaçam a Amazônia em seus povos e natureza exuberantes. Uma espiritualidade que integre as dimensões divina, humana e cósmica de toda a Realidade. Ou seja, uma experiência de profundo resgate do que constitui o ser humano como filho de Deus e responsável pelo cuidado e preservação com toda a criação.

\section{Sínodo para a Amazônia, uma provocação-convocação}

Não são poucos os motivos que nos provocam a reflexão sobre o que está acontecendo na Amazônia e sobre o nosso papel diante dessa realidade. Somos convocados a uma mudança de atitude e de postura perante o que nos é apresentado como ameaça à vida humana e à sobrevivência do planeta. E, nesse sentido, para a realização da missão da Igreja Católica acredita-se que "evangelizar é tornar o Reino de Deus presente no mundo". ${ }^{7}$ Logo, partindo dessa compreensão, é-lhe exigido entender o tempo presente com as suas

\footnotetext{
${ }^{6}$ PANIKKAR, R., La nueva inocencia, p. 55. Panikkar em algumas ocasiões recorda São Victor fazendo menção dos três olhos que participam nas três formas de conhecimento: o olho da carne, o olho da mente e o olho do espírito (carnis, mentis et fidei). PANIKKAR, R., De la mística, p. 183. Ricardo de São Victor e Juan de Findenza (conhecido como são Boaventura, franciscanos do século XIII) falaram pela primeira vez dos "três olhos" como forma de ter acesso ao conhecimento.
}

${ }^{7} \mathrm{EG} 176$. 
características, desafios e necessidades específicas, em uma atitude sensível à avassaladora desigualdade social, cultural e econômica, assim como quanto à pobreza que assola o mundo e, dessa forma, estar atenta às necessidades do ser humano em todas as suas dimensões.

Essa compreensão parte da experiência de fé do cristão que encontra em Jesus Cristo a razão de sua preocupação com a vida de todas as pessoas, e, dessa forma, empenhe-se para que a todos seja proporcionado um desenvolvimento integral. Pois, reconhece que a ação criadora de Deus, original e nova a cada momento, abrange a sua preocupação ordenadora e preservadora. Ele é o totalmente Outro e, sem pressupor qualquer coisa além de si, cria a partir de si mesmo, como criação de sua livre vontade. E, dessa forma, efetua criadoramente vida e salvação de suas criaturas, contando com a colaboração do ser humano, que, criado à sua imagem e semelhança, é-lhe concedido a participação no cuidado da sua criação. ${ }^{8}$

Consequentemente, a postura do cristão diante da criação é de assumir a sua responsabilidade no cuidado da mesma. E, assim, diante das inúmeras injustiças, tomar a decisão por cooperar na transformação das causas estruturais que promovem a pobreza, a degradação do meio ambiente e as mais diversas desigualdades. Uma importante parcela dessa contribuição se encontra no cotidiano da vida, em gestos de solidariedade, de compaixão e de cuidado que lenta e profundamente fecundam uma nova relação entre as pessoas, com Deus e com a natureza; na promoção de uma nova compreensão sob o significado de viver em comunidade, onde todos se sentem responsáveis uns pelos outros; na acolhida do dom de Deus espalhado no universo, onde cada um assume a natureza como fonte de aprendizado e humanização, e assumindo que tudo isso está interligado.

É importante entender que todas essas contribuições não devem se tornar ações esporádicas, mas sim criar uma nov+a mentalidade que desperte convicções e práticas, capazes de significativas mudanças estruturais, porque é urgente "crescer numa solidariedade que permita a todos os povos tornarem-se artífices do seu destino, tal como cada homem é chamado a desenvolver-se", 9 uma vez que é um imperativo para todos os cristãos estar atento ao clamor dos pobres.

Por que ofuscar o que é tão óbvio no ensinamento de Jesus? A demasiada preocupação por não cair em erros doutrinais, descuidando-se da fidelidade

\footnotetext{
${ }^{8}$ SATTLER, D.; SCHNEIDER, T., Doutrina da Criação, p. 145-147.

${ }^{9}$ EG 190.
} 
ao ensinamento de Jesus, pode levar a uma prática cristã cada vez mais distante da beleza do Evangelho "que nem sempre a conseguimos manifestar adequadamente, mas há um sinal que nunca deve faltar: a opção pelos últimos, por aqueles que a sociedade descarta e lança fora"; longe desse seguimento, a alienação afeta a pessoa na compreensão de quem é Jesus Cristo e, consequentemente, toda a realidade a sua volta. ${ }^{10}$

Por conseguinte, dirigindo-se à Igreja, diz o Papa Francisco: "os Pastores, acolhendo as contribuições das diversas ciências, têm o direito de exprimir opiniões sobre aquilo que diz respeito à vida das pessoas, dado que a tarefa da evangelização implica e exige uma promoção integral de cada ser humano". ${ }^{11} \mathrm{E}$, assim acolhendo as contribuições das várias ciências, é-nos apresentado, na Laudato $\mathrm{Si}^{\prime}$, um panorama muito significativo para entendermos a crise social e ambiental que, diante da gravidade de suas consequências que devastam o mundo, segundo o Papa Francisco, leva-nos a constatar que "não há duas crises separadas: uma ambiental e outra social, mas uma única e complexa crise socioambiental". Ele insiste em dizer que, diante dessa realidade, faz-se necessária "uma abordagem integral para combater a pobreza, devolver a dignidade aos excluídos e, simultaneamente, cuidar da natureza". ${ }^{12}$

Com o olhar voltado para o nosso país, deparamo-nos com um sistema político e econômico que, cada vez mais, tem se revelado defensor do mercado em detrimento do ser humano e do cuidado com a natureza. Somado à essa realidade o que nos aponta o Papa Francisco em sua reflexão, encontramo-nos em um complexo contexto, que ousamos denominar como crise theós-antrôpos-kósmos, ${ }^{13}$ por atingir as dimensões do divino, do humano e do cosmos, que deveriam estar integradas. O que constatamos é a negação, o desprezo pelo ser humano e por tudo que lhe é vital. Uma vez que na ambição do lucro não existe espaço para pensar na natureza, na sua importância para as pessoas e as culturas, no interesse e na necessidade, em especial dos mais vulneráveis da sociedade. Além disso, muitas pessoas no mundo negligenciam sua coparticipação, junto ao Criador, no cuidado e na preservação de toda a criação.

\footnotetext{
${ }^{10}$ EG 194-196.

${ }^{11}$ EG 182.

${ }^{12} \operatorname{LS} 139$.

${ }^{13} \mathrm{O}$ místico e teólogo Raimon Panikkar desenvolverá o termo intuição cosmoteândrica para integrar essas três dimensões da Realidade. Abordaremos esse conceito mais adiante.
} 
Se não assumirmos a nossa responsabilidade diante dessa realidade e rompermos com a lógica perversa que insiste em desprezar o ser humano continuaremos sem enfrentar uma das causas de toda a crise em que nos encontramos. Pois é certo que a pobreza, que se aprofunda com as desigualdades não é um problema, simplesmente, técnico, mas humano e ético. Mesmo que para alguns a política econômica e a tecnologia possam resolver os problemas sociais e ambientais, para o Papa Francisco, "o mercado, por si mesmo não garante o desenvolvimento humano integral nem a inclusão social". ${ }^{14}$

Logo, reconhecemos que, para "tornar o Reino de Deus presente no mundo" não é possível para o cristão permanecer alheio às diversas realidades que contextualizam o seu campo de missão. A orientação do Papa Francisco é que "cada cristão e cada comunidade há de discernir qual o caminho que o Senhor lhe pede, mas todos somos convidados a aceitar esta chamada: sair da própria comodidade e ter a coragem de alcançar todas as periferias que precisam da luz do Evangelho". ${ }^{15}$

Acolher esta chamada é sair de si mesmo para assumir a responsabilidade pelos demais, é alargar a visão e o coração para acolher e respeitar as diferenças. É também se deixar transformar pela profundidade que é a experiência com Deus, humanizadora, integral e integradora. Dessa forma, quando alguém tem seus direitos, sua liberdade e costumes desrespeitados, a exemplo dos povos originários da Amazônia, todos os cristãos são atingidos, pois a sua missão evangelizadora é desejar e promover uma sociedade cujo desenvolvimento gere democracia, valorize a liberdade e a igualdade, respeite as diferenças, promova e defenda a vida em todos os seus sentidos, zele e preserve a natureza.

Isso posto, procuraremos abordar as contribuições de uma experiência religiosa, para o futuro da Amazônia, a partir da construção de uma espiritualidade capaz de encurtar distâncias, ultrapassar fronteiras, sentir com os demais as suas dores e alegrias, ${ }^{16}$ de oferecer a vida, de ser capaz de prestar atenção à beleza e amá-la, de reconhecer o dom que é toda a criação, ou seja, de reconciliar e integrar todas as dimensões: divina, humana e cósmica de toda a Realidade. Mas antes vamos entender a Amazônia como um lugar que além de nos provocar e convocar a uma mudança de atitude, também interpela a nossa existência.

\footnotetext{
${ }^{14}$ LS 109.

${ }^{15}$ EG 20.

${ }^{16}$ GS 1.
} 


\section{Amazônia, um lugar que interpela a vida}

A Amazônia assume esse lugar porque na voz que ecoa dos pobres e na destruição silenciosa da natureza se encontra o Espírito de Deus, "um espaço onde o próprio Deus se manifesta e chama os seus filhos". ${ }^{17}$ Diante desses clamores, faz-se necessário o silêncio para a construção de uma nova visão contemplativa, capaz de misericórdia e de compromisso. É um território onde Deus interpela a Igreja, um lugar para a experiência pascal. Lugar onde a dor e a violência estão presentes na destruição da natureza e da vida humana, sem deixar de ser também um lugar de esperança e do "bem viver", pois é um lugar onde tudo é compartilhado, onde não existe separação nem divisão entre as partes [...] onde não há espaço para a ideia de indivíduo separado da comunidade ou de seu território. ${ }^{18}$

O desafio se estabelece porque nesse território há uma vasta dimensão geográfica, uma grande diversidade biológica e cultural ainda não adequadamente compreendidas, respeitadas e assumidas pelas atividades pastorais da Igreja. O que exige humildade e desprendimento porque o processo de conversão ao qual a Igreja é chamada implica desaprender, aprender e reaprender. Este caminho exige uma visão crítica e autocrítica que nos permita identificar aquilo que devemos desaprender, o que prejudica a Casa Comum e seus povos porque

aprendendo com os povos nativos, podemos contemplar a Amazónia, e não apenas analisá-la, para reconhecer esse precioso mistério que nos supera; podemos amá-la, e não apenas usá-la, para que o amor desperte um interesse profundo e sincero; mais ainda, podemos sentir-nos intimamente unidos a ela, e não só defendê-la: e então a Amazónia tornar-se-á nossa como uma mãe. ${ }^{19}$

Dessa forma, a partir de todo o processo de conversão desejado para a Igreja, em que a sua mentalidade é transformada, será possível assumir as causas da situação eclesial e de todos os povos, etnias e culturas que compõem o território Pan-Amazônico, como um Pentecostes. Para tanto, a Igreja deve crescer na Amazônia, moldar a sua própria identidade na escuta e diálogo com

\footnotetext{
${ }^{17}$ Querida Amazônia, 57.

${ }^{18}$ Querida Amazônia, 20.

${ }^{19}$ Querida Amazônia, 55.
} 
as pessoas, realidades e histórias do território, ${ }^{20}$ capaz de uma evangelização inculturada que "será sempre a salvação e libertação integral de um povo ou grupo humano determinado, que fortalecerá sua identidade e confiança em seu futuro específico, criando oposição aos poderes da morte". ${ }^{21}$

Ricamente, por meio dos "diferentes povos, que experimentam o dom de Deus segundo a própria cultura, a Igreja exprime a sua genuína catolicidade e mostra a "beleza deste rosto pluriforme". ${ }^{22}$ A dinâmica que anima a inculturação da fé "não é um processo de cima para baixo, nem uma imposição externa, mas um mútuo enriquecimento das culturas em diálogo (interculturalidade); aqui o sujeito é o próprio povo indígena e os demais povos existentes na Pan-Amazônica.

Assim, "a partir do coração do Evangelho, reconhecemos a conexão íntima que existe entre evangelização e promoção humana, que se deve necessariamente exprimir e desenvolver em toda a ação evangelizadora". ${ }^{23} \mathrm{~A}$ missão da Igreja é evangelizar, o que implica se empenhar no comprometimento com a salvação integral da pessoa humana. E, diante de tantas vozes, ela é exortada a ter novas respostas às mais diversas situações, e indicar caminhos para um novo kairós para a Igreja e o mundo.

Partindo da compreensão de que as dimensões humanas, social e ecológica estão todas interligadas e que se relacionam entre si, tendo em vista que, "hoje, a análise dos problemas ambientais é inseparável da análise dos contextos humanos, familiares, laborais, urbanos, e da relação de cada pessoa consigo mesma, que gera um modo específico de se relacionar com os outros e com o meio ambiente", ${ }^{24}$ acreditamos ser esse o desafio para vários povos, em especial falamos da realidade Pan-Amazônica.

A partir de tudo o que já foi apresentado, damo-nos conta de que o ser humano deve se reconhecer como colaborador (ativo ou passivo) de toda a escandalosa realidade que assola a região Pan-Amazônica, pelo fato de, simplesmente, constatar que tudo está interligado: o humano, o divino e o cosmos. Dessa forma, faz-se urgente uma mudança de consciência que permita rememorar que a sua salvação se realiza com a salvação do mundo, pois a criação e a obra salvífica não podem ser dissociadas (Ef 1,3-14).

\footnotetext{
${ }^{20}$ Querida Amazônia, 66.

${ }^{21}$ DSD 243.

${ }^{22}$ EG 116.

${ }^{23} \mathrm{EG} 178$

${ }^{24} \operatorname{LS} 141$.
} 
Isto posto, encontramos na intuição cosmoteândrica, apresentada por Raimon Panikkar, um caminho para essa mudança de consciência, pois enquanto revela a dimensão cósmica do homem, revela também as dimensões humana e divina do cosmos. Esta noção não fragmentária da realidade aponta para a ecosofia, sabedoria da/e sobre a terra, uma forma diferente de compreender a relação Homem-Mundo sem esquecer sua relação com Deus.

\section{Toda realidade é cosmoteândrica}

Estamos diante da concepção nuclear do pensamento de Panikkar, o seu neologismo, a intuição cosmoteândrica. Para ele é a intuição totalmente integrada do "tecido sem costuras da realidade inteira", ${ }^{25}$ que expressa aquela "visão da realidade que compreende o divino, o humano e o cósmico". ${ }^{26}$ Assim sendo, a Realidade é trinitária e tem uma dimensão divina, uma dimensão humana e uma dimensão material.

Suas "realidades" podem diferenciar-se, porém não se separar. Não existe nem monismo, nem dualismo, trata-se de uma relação a-dual (advaita). Isto é o característico do princípio cosmoteândrico. Para Panikkar toda a Realidade é cosmoteândrica, e se o ser humano faz parte dessa realidade, ele é uma realidade cosmoteândrica. $O$ princípio cosmoteândrico nos ajuda a reconhecer que o divino, o humano e o terreno são as três dimensões irredutíveis que constituem o real. ${ }^{27} \mathrm{~A}$ visão cosmoteândrica supera a dialética porque descobre a estrutura trinitária de tudo:

Não existem três realidades: Deus, o Homem e o Mundo; porém tampouco existe uma, ou Deus, ou Homem ou Mundo. A realidade é cosmoteândrica. É nossa forma de olhar que faz com que a realidade nos pareça, às vezes, sob um aspecto e às vezes sob outro. Deus, Homem e Mundo estão por assim dizer, em uma íntima e constitutiva colaboração para construir a realidade, para fazer avançar a história, para continuar a criação. Não se trata de que o Homem esteja trabalhando duramente aqui embaixo, enquanto Deus o supervisiona das alturas com vista a recompensá-lo ou a castigá-lo e que o Mundo permaneça impassível às elucubrações da mente humana. ${ }^{28}$

\footnotetext{
${ }^{25}$ PANIKKAR, R., La intuición cosmoteándrica, p. 19.

${ }^{26}$ PANIKKAR, R., El mundanal silencio, p. 26.

${ }^{27}$ PANIKKAR, R., El mundanal silencio, p. 82.

${ }^{28}$ PANIKKAR, R., La Trindad, p. 93.
} 
As dimensões da Realidade: Deus, Homem e Mundo coexistem estão inter-relacionadas e podem ser hierarquicamente integradas, no entanto não podem ser isoladas, isto as aniquilaria. ${ }^{29}$ De acordo com o próprio Panikkar, sua intuição cosmoteândrica "representa a consciência religiosa que está aflorando em nosso tempo". ${ }^{30}$ Pois se percebem sinais de ressurreição na raiz da sensibilidade ecológica, nela existe uma veia mística; na imagem que o homem projeta de si mesmo existe uma necessidade de infinito. E no mesmo coração do divino existe um impulso para o tempo, o espaço e o homem.

\subsection{O ser humano, uma realidade cosmoteândrica}

Como já foi dito, o ser humano é uma realidade cosmoteândrica por participar de sua natureza, enquanto ser da realidade: a) possui uma dimensão abissal, transcendente e imanente. Ao ter uma dimensão divina, participa de uma infinita inesgotabilidade, de caráter aberto; é um mistério, é liberdade. b) possui uma dimensão da consciência, propriamente "humana", aquela que permite estar no Mundo, compartilhar sua secularidade, mover-se nas coordenadas do espaço e tempo, não de forma acidental, senão de forma constitutiva. Por isso, o homem é espírito, alma e corpo. As três dimensões do ser humano (realidade ad intra) não são outra coisa que o reflexo da perichoresis entre Deus-Homem-Mundo (realidade ad extra). ${ }^{31}$

A integração da aventura trinitária a toda a Realidade não diminui nem a transcendência divina nem a diferença entre Deus e o Mundo, de maneira análoga a unidade trinitária não elimina a diferença entre as pessoas divinas. ${ }^{32}$

O ser do Homem não pode ser reduzido a uma "pura natureza" teórica. Sua vocação desde o princípio é ser Filho de Deus, uno com o Filho único. Considerar o Homem como um simples "animal racional" é negar-lhe o direito a seu verdadeiro fim e privá-lo da esperança de alcançá-lo, pois, "Deus é o fim, o limite do Homem". ${ }^{33}$

\footnotetext{
${ }^{29}$ PANIKKAR, R., La Trindad, p. 98.

${ }^{30}$ PANIKKAR, R., La Trindad, p. 99.

${ }^{31}$ PANIKKAR, R., La intuición cosmoteândrica, p. 82-85.

${ }^{32}$ PANIKKAR, R., La Trindad, p. 90.

${ }^{33}$ PANIKKAR, R., La Trindad, p. 92.
} 
Ou seja,

o ser humano experimenta a profundidade de seu próprio ser, descobre e sente que em seu ser existe algo mais, um plus que está por construir, que pertence a seu ser privado e ao mesmo tempo o transcende. Descobre outra dimensão que não pode manipular. Sempre existe algo mais do que os olhos podem ver, do que a mente pode encontrar ou do que pode comover ao coração. Este mais - mas do que pode perceber, entender e sentir representa a dimensão divina. ${ }^{34}$

Panikkar recupera a natureza mediadora do ser humano, "aquilo que nós somos, nosso ser, é precisamente mediação". ${ }^{35}$ Esta ideia permite estabelecer outra de maior profundidade que aprofunda suas raízes no cristianismo primitivo: o ser humano é um sacerdote cósmico. "O homem é um sacerdote do universo, é um mediador entre o céu e a terra". ${ }^{36}$

Como já tínhamos dito, a relação Deus-Homem-Mundo é a-dual. A ruptura da harmonia entre Deus-Homem-Mundo não é somente de tipo epistemológico, é existencial. Quando o ser humano rompe sua relação com a terra, querendo bastar-se a si mesmo, torna-se um monstro; querendo dominála, destrói a si mesmo. Quando rompe sua relação com os céus, querendo conduzir-se a si mesmo, se converte em uma automotriz que destrói os demais. ${ }^{37}$ Nesse sentido, o homem, o divino e o cosmos coexistem, permanecem interrelacionados e podem estar constituídos ou coordenados hierarquicamente. ${ }^{38}$

Tudo está relacionado com o todo, cada parte deste todo é diferente. Cada um é um nó único na rede de relações que constitui a Realidade. Quando este nó rompe os fios que os une a outros nós, não permitindo a liberdade constitutiva da inter-in-dependência entre os nós, em última instância, com a realidade, nasce o individualismo que perturba a harmonia e leva a morte da pessoa fazendo-a perder sua identidade que é também relacional. ${ }^{39}$

Se o Homem é uma realidade cosmoteândrica, então é Terra, Cosmos, Natureza; se é Terra, não podo ter uma relação de oposição com ela; se é

\footnotetext{
${ }^{34}$ PANIKKAR, R., La Trindad, p. 96.

${ }^{35}$ PANIKKAR, R., Experiencia de Dios, p. 36.

${ }^{36}$ PANIKKAR, R., Der Mensch ein trinitarisches Mysterium, p. 177 Apud RUEDA, J. L. M., La antropología de Raimon Panikkar y su contribución a la antropología teológica cristiana, p. 106.

${ }^{37}$ PANIKKAR, R., Paz y desarme cultural, p. 49.

${ }^{38}$ PANIKKAR, R., La nueva inocencia, p. 51-52.

${ }^{39}$ PANIKKAR, R., La nueva inocencia, p. 16.
} 
Cosmos, é necessária uma mudança radical de atitude; e se é Natureza, sua salvação (de ambos) depende dessa nova forma de estarem juntos. ${ }^{40} \mathrm{O}$ homem compartilha a natureza divina e, em virtude desta condição, é chamado a alcançar a divinização pela graça do Espírito que o habita.

Segundo Panikkar, o Mundo não é uma matéria inerte. Com essa a firmação, ele vai além do resgate da responsabilidade do ser humano com a criação que, por ser "imagem e semelhança de Deus", não deveria contribuir para a exploração irresponsável do mundo para não correr o risco de afastarse de sua divinização. ${ }^{41}$ Logo, partindo da compreensão de que a Terra é viva, "significa que podemos entrar em uma relação pessoal com ela" ${ }^{42}$ No entanto, não se trata de uma relação acidental, trata-se de uma relação constitutiva. E assim, a plenitude do ser humano se alcança por meio desta relação, mesmo que não seja apenas por ela.

A Terra é viva porque nela habita a Vida, por reconhecer a dimensão material da realidade como um efeito da relação pericorética Deus-HomemMundo: "Deus e o mundo não são dois seres independentes e autossuficientes. O mundo pode ser distinto de Deus, porém não é nem independente nem está separado dEle". ${ }^{43}$ Nessa mesma direção, Müller disse: "a usual expressão 'Deus se afastou da criação' é pouco exata e não passa de uma simples metáfora. Deus não pode se afastar da criação, pois se afundaria imediatamente no nada. É impossível que Deus se afaste de seu ato criador". ${ }^{44}$ E, segundo Moltmann, se descobrimos no mundo os vestígios de Deus, então também poderemos descobrir a "imagem de Deus" em nós mesmos. ${ }^{45}$

De tal modo, na perspectiva de Rahner ${ }^{46}$ se entende a criação, em seu conjunto, como uma autorrevelação de Deus por meio da criação, e por ela mediada. Ao conceber e aceitar as criaturas conscientes e livremente, e sua autorrealização como uma participação no autoconhecimento e no amor de Deus, faz-se Deus presente nelas. "Porque o que se pode conhecer de Deus é manifesto entre eles, pois Deus lho revelou. Sua realidade invisível - seu eterno poder e sua divindade - tornou-se inteligível, desde

\footnotetext{
${ }^{40}$ RUEDA, J. L. M., Ecosofia, p. 122.

${ }^{41}$ MÜLLER, G., Dogmática, p. 111.

${ }^{42}$ PANIKKAR, R., Anima mundi-vita hominis-spiritus, p. 4.

${ }^{43}$ PANIKKAR, R., Misterio y revelación, p. 94.

${ }^{44}$ MÜLLER, G., Dogmática, p. 219.

${ }^{45}$ MOLTMANN, J., Dios en la creación, p. 111.

${ }^{46}$ RAHNER, K., Curso fundamental da fé, p. 237.
} 
a criação do mundo, através das criaturas, de sorte que não têm desculpa" (Rm 1, 19-20).

Logo, existe uma interdependência entre Deus e o Mundo, cuja ênfase se encontra na sua relação. Na linguagem cristã, pode-se dizer que Deus "gera" seu Filho, no qual o novo céu e a nova Terra estarão presentes, quando tudo estiver plenamente realizado (Ap 21,1). O ato com o qual o Pai gera seu Filho é o mesmo com o qual ele também "cria" o mundo (Tomás de Aquino, Sum.Th. I, q.34, a.3, c). O ato simples e total de Deus, então, não é a criação, mas a geração de todo o Corpo - ou corpo místico, como diriam os cristãos, isto é, Cristo. Para expressar a mesma intuição em outros termos, poderíamos dizer que, ao criar, Deus simplesmente permanece Deus. Agora, da mesma maneira que "ser" é o ato com o qual Deus se expressa, Deus também é Deus indo além de si mesmo em puro "crescimento", por assim dizer, em uma explosão sempre nova e inédita, sem passado e sem futuro. O mundo nada mais é do que uma realidade incompleta em processo para sua divinização, chamado a participar desse ato de "crescimento" divino. ${ }^{47}$

Encontramos Cristo ao lado do Pai no papel de criador, embora em diferentes planos. O Pai é o princípio e o fim, e Cristo é o mediador da criação e da salvação. Com a criação temos a constituição do corpo místico, ou, podemos dizer, do Cristo cósmico. O texto se diferencia de outras cosmovisões e até mesmo da fé judaica ao atribuir a perspectiva cosmológica a Jesus, uma perspectiva cristológica que estendeu a soteriologia à cosmologia. ${ }^{48}$ Por este motivo, encontramos uma relação direta entre Cristo e a criação. O hino aos colossenses é bem explícito ao afirmar: "nele foram criadas todas as coisas, no céu e na terra, tudo foi criado por Ele e para Ele; Ele é antes de tudo e tudo nele subsiste ( $\mathrm{Cl}$ 1,16-17).

Talvez Panikkar tenha se inspirado em São Paulo, já que o apóstolo utiliza estas proposições para expressar a inter-retro-penetração de Deus no mundo e do mundo em Deus, pois "Cristo é tudo em todos" (Cl 3,11). Está evidente a inter-penetração (pericorese) de Cristo na criação, do Espírito que a preenche com a sua plenitude. No entanto, a dimensão cósmica de Cristo não se reduz à sua mediação. Cristo é o primogênito de toda criação. O Filho feito carne é a imagem do Deus invisível, o que situa a criação sob o signo da encarnação.

${ }^{47}$ PANIKKAR, R., Mito, fe y hermenéutica, p. 108.

${ }^{48}$ DE LA PEÑA, J. L., Teología de la Criación, p. 59. 
O mundo tem origem e destino em Cristo. Logo, a criação é cristocêntrica. E dessa forma, o universo assume seu sentido último e definitivo em Jesus Cristo e a criação sua índole soteriológica por meio da ressurreição. ${ }^{49}$

Para Panikkar, ${ }^{50}$ a criação é o primeiro ato do drama cosmoteândrico da Realidade: o sacrifício de Deus corresponde ao sacrifício do homem; sua criação, sua divinização. Para a teologia cristã "a criação é o primeiro passo na história da salvação". A redenção não é uma espécie de acidente histórico na aventura cosmoteândrica, não está condicionada apenas pelos assuntos humanos, pertence a mesma economia da Realidade. Esse primeiro ato poderia ser imaginado como um "ato temporal", que ocorre apenas uma vez, mas não é. Trata-se de um ato sempre novo, contínuo, permanente em sua novidade: a criação contínua. ${ }^{51}$

\subsection{Ecosofia: um caminho para uma espiritualidade cosmoteândrica}

Nesse contínuo gesto criador de Deus, encontra-se toda a criação. Dessa forma, a relação Homem-Mundo, a partir da teologia ecológica, é enriquecia pela abordagem que realiza Panikkar sobre a ecosofia. A questão ecológica incide sob a teologia, tanto no que diz respeito às relações entre o mundo e o ser humano, como também na perspectiva da busca por si mesmo ou por causa de sua responsabilidade. $\mathrm{O}$ ponto de partida é a consciência da relação que existe entre todos os seres vivos.

Neste sentido, Panikkar propõe uma espiritualidade cosmoteândrica:

Quisera utilizar a palavra "espiritualidade" de maneira válida para todas as diferentes vias que conduzem o homem ao seu destino [...]. A espiritualidade deve ser integral e não pode deixar de lado nenhum aspecto da realidade. Tudo tem que ser "purificado pelo fogo", tudo deve ser transformado: é a apokatastasis que nos fala são Pedro $(1 \mathrm{pd} 3,11) .{ }^{52}$

Entendemos que a espiritualidade como "a atitude básica do homem com respeito ao seu fim último" 53 e a contemplação como "mediação

\footnotetext{
${ }^{49}$ DE LA PEÑA, J. L., Teología de la Criación, p. 59-65.

${ }^{50}$ PANIKKAR, R., Mito, fe y hermenêutica, p. 112-113.

${ }^{51}$ ABUMALHAM, M., Presentación, p. 13 Apud RUEDA, J. L. M., Ecosofia, p. 129.

${ }^{52}$ PANIKKAR, R., La nueva inocencia, p. 314-317.

${ }^{53}$ PANIKKAR, R., La Trindad, p. 37.
} 
cosmoteândrica" 54 falam da mesma realidade. O ser humano que vive esta experiência é sensível às relações constitutivas da Realidade. ${ }^{55}$ A espiritualidade cosmoteândrica não fica apenas na relação Deus-Homem; inclui o mundo nesta comunhão, posto que Deus, Homem e Mundo formam uma relação nãodualista.

Para incluir todas as dimensões, faz-se necessário, então, uma atenção especial com a ecologia. Segundo Panikkar, esta foi reduzida a uma ciência pragmática, preocupada para que a natureza seja mais bem explorada. $\mathrm{Ou}$ seja, não mudamos a nossa mentalidade, a terra continua sendo objeto de exploração de recursos, que devemos garantir para que durem o maior tempo possível. ${ }^{56}$ Por conseguinte,

tudo isso representa grandes passos na direção certa; mas o próprio vocabulário que fala de exploração, recursos, necessidades, desenvolvimento etc. sugere que a cosmologia subjacente permanece inalterada. Do mesmo modo que hoje se entende que o homem é (também) corpo e não apenas possui um corpo, devemos retornar à velha sabedoria, que nos diz que o homem é terra e não apenas que ele habita na terra..$^{57}$

O termo ecosofia, segundo Panikkar, constata a limitação do termo ecologia que, no saber científico, orienta a sua ação ao manejo e controle da natureza dentro de uma visão antropocêntrica e racionalista da realidade. Dessa forma, mesmo que a ecologia tenha nos despertado para esse problema, precisamos avançar, pois agora "é a nossa atitude em relação à terra que deve mudar radicalmente". ${ }^{58}$ A palavra ecosofia nos remete a um termo composto pelas palavras gregas oikos, que significa casa, e sophia, que significa sabedoria. Essa palavra nos sugere o reconhecimento de uma sabedoria presente em nossa oikos, presente em muitas cosmovisões de povos indígenas que têm revelado novos paradigmas de convivência com a terra. Contudo, têm sido eclipsados por interferências externas que muitas vezes desestabilizam suas crenças e tradições. Panikkar chamou esse fato de "a perda da experiência do cosmos na

\footnotetext{
${ }^{54}$ PANIKKAR, R., La nueva inocencia, p. 65.

${ }^{55}$ PANIKKAR, R., Humanismo y cruz, p. 43.

${ }^{56}$ PANIKKAR, R., De la mística, p. 202.

${ }^{57}$ PANIKKAR, R., El espíritu de la política, p. 10.

${ }^{58}$ PANIKKAR, R., Ecosofía, p. 114.
} 
vida humana". Esse termo indica "a experiência mística da matéria em geral e da Terra em particular. Logo, ecosofia é aquela sabedoria que nos faz sentir que a Terra é também um sujeito, e mais ainda, uma dimensão constitutiva e definitiva da realidade". ${ }^{59}$

[Ecosofia] revela que a terra - como nós - é limitada, finita; e que temos relações estreitas, constitutivas e, portanto, recíprocas com ela. É uma nova e velha sabedoria. No que diz respeito à nossa pergunta, a ecosofia nos revela que as fronteiras dos estados são artificiais e não naturais; que a poluição não reconhece passaportes, que o ozônio na atmosfera não está sujeito à soberania de um único estado; que as nuvens são mensageiras do amor, mas também da chuva ácida [...] nos mostra a interdependência do mundo. $^{60}$

A palavra ecosofia expressa a ideia de uma sabedoria cosmológica. Segundo Panikkar, o cosmos não pode ser entendido sem sua relação com a dimensão divina e humana da Realidade. Ela é a sabedoria que equilibra estas dimensões da Realidade, "a harmonia é justamente este jogo natural, espontâneo, livre, entre estas dimensões, por que um novo equilíbrio? Porque cada momento é novo". ${ }^{61}$

E assim a espiritualidade cosmoteândrica realiza a síntese harmônica das três dimensões da vida: Deus, Homem e Mundo. Nela existe a contemplação, que é algo mais que pensamento; ação, que não limita seu horizonte à construção da cidade terrena. Deus, que não seja unicamente um juiz ou um vigia. Amor, que ultrapasse todo sentimentalismo. Oração que não se limita à petição, nem sequer a louvores, senão seja também silêncio, sem cair na indiferença. Apofatismo, que não caia no niilismo. Graça que não seja antinatural. Espaço e tempo, que não são passageiros, mas dinamismos criadores. E, sobretudo, inteligência, que nos permite falar conscientes e responsavelmente de tudo isso. ${ }^{62}$

Pois, tendo em vista que a ecosofia aponta para o descentramento do ser humano, "todos os esforços para a salvação pedem uma genuína integração com o universo inteiro". ${ }^{63}$

\footnotetext{
${ }^{59}$ PANIKKAR, R., De la mística, p. 202.

${ }^{60}$ PANIKKAR, R., El espíritu de la política, p. 107-108.

${ }^{61}$ PANIKKAR, R., Ecosofia, p. 116.

${ }^{62}$ PANIKKAR, R., La Trindad, p. 99.

${ }^{63}$ PANIKKAR, R., La nueva inocência, p. 329.
} 
A dolorosa descoberta do homem moderno de que ele não é mais o dono do universo, mas um colaborador ou administrador responsável, é uma experiência religiosa básica. A religiosidade humana não pode ser dissociada desta terra - o oikos típicos de qualquer ecumenismo, o habitat da família humana. ${ }^{64}$

Panikkar reconhece o ser humano como o ser onde transita o logos, no entanto, como já vimos, para o autor, a Realidade não se reduz ao logos humano, por isso ele afirma: "Eu não sou homocêntrico. Não acredito que podemos falar do homem separado de Deus e separado do cosmos: vivemos todos a mesma aventura". ${ }^{65}$ Ou seja, a experiência humana não precisa ser antropocêntrica, ainda que isso não significa afastar-se do ser humano. Segundo o conceito de ecosofia, se a consciência impregna todo o ser, entranha uma nova forma de ver o ser humano, ele não é apenas um indivíduo, mas uma pessoa, ou seja, um ser de relações. Para Panikkar, "individualizar o ser humano é cortar o cordão umbilical que lhe dá a vida", ${ }^{66}$ pois não existe ser humano sem Deus e ser humano sem Mundo.

Dessa forma, a ecosofia é um convite à uma experiência de profundidade em Deus, como bem assinala a espiritualidade cosmoteândrica:

O conhecimento de todas as coisas em si e de si mesmo em todas as coisas implica a união a-dual entre o microcosmo e o macrocosmo. Esta é a experiência da Realidade do corpo místico. A sensibilidade que estamos descrevendo é aberta ao mundo exterior e, também, ao interior, ao cultivo da política e ao cultivo do espírito, à preocupação com os outros e com ele mesmo [...] A visão mística inclui tanto o Outro (alter) quanto o Eu, tanto para a Humanidade como para a Terra e para o Divino. É a experiência cosmoteândrica. $\mathrm{O}$ restante são reducionismos. ${ }^{67}$

Ou seja, a madura espiritualidade não será um jogo dialético entre as três formas de vida ou a especialização reducionista de uma das três, mas uma síntese harmônica entre as três dimensões constitutivas da Realidade. "Uma espiritualidade cuja mais simples expressão seria: o Homem é algo mais que 'homem': é um mistério cosmoteândrico. Deus, o Homem e o Mundo estão

\footnotetext{
${ }^{64}$ PANIKKAR, R., La nueva inocência, p. 329.

${ }^{65}$ PANIKKAR, R., Ecosofia, p. 45.

${ }^{66}$ PANIKKAR, R., La intuición cosmoteándrica, p. 97.

${ }^{67}$ PANIKKAR, R., De la mística, p. 186.
} 
comprometidos, embora diferentemente, em uma mesma aventura. E esta é nossa dignidade". ${ }^{68}$ Uma vez que,

a noção de que o ser humano, como parte integrante da terra, sobrevive com ela, caso viver com ela, ou perece com ela, caso viver em oposição a ela, significa teologicamente: quem malbarata a salvação da criação que the foi confiada, malbarata sua própria salvação. A destruição da criação é uma negação do Deus Criador e uma negação da salvação pretendida por ele na criação. Não somente o ser humano está inserido no biótopo terra, mas a história da salvação como um todo está enfeixada na história da terra. ${ }^{69}$

No entanto, não significa, nesta relação, evitar as diferenças, mas perceber as inter-relações e conscientizar-se da interdependência existente entre Deus, o Homem e o Mundo. Esta espiritualidade curaria a ferida aberta do ser humano moderno: o abismo entre o material e o espiritual e, com isso, entre o secular e o sagrado, o inferior e o exterior, o temporal e o eterno. ${ }^{70}$

\section{Conclusão}

A partir da nossa reflexão sobre o futuro da Amazônia e sobre a convocação do Papa Francisco para o Sínodo da Amazônia, bem como a apresentação do pensamento do místico e teólogo Raimon Panikkar, vislumbramos um caminho para a construção e o aprofundamento de uma espiritualidade que esteja comprometida com a transformação de um contexto que, cada vez mais, tem exigido a integração entre as dimensões divina, humana e cósmica da Realidade.

Por isso, urge que o ser humano realize uma experiência de mergulho no que há de mais profundo em si mesmo, que o possibilite descobrir em toda a criação a dimensão de profundidade, de infinito que existe em tudo. E como o encontro com Deus é uma experiência de Vida, ela é sensível, intelectual e espiritual, é humana, em sua plenitude, e supera toda alienação sem cair no solipsismo. Segundo Panikkar, "é uma experiência não só possível, mas também necessária para que todo ser humano chegue à consciência de sua própria identidade". ${ }^{71}$

\footnotetext{
${ }^{68}$ PANIKKAR, R., La Trindad, p. 99.

${ }^{69}$ SATTLER, D.; SCHNEIDER, T., Doutrina da Criação, p. 147.

${ }^{70}$ PANIKKAR, R., La intuición cosmoteándrica, p. 180.

${ }^{71}$ PANIKKAR, R., Experiencia de Dios, p. 76. Ou seja, "o ser humano chega a ser plenamente humano quando faz a experiência do seu último 'fundamento', do que realmente é”.
} 
A experiência de Deus é a raiz de toda experiência humana. Ela é subjacente a toda vivência humana que tem como requisito indispensável a integração do interior humano, em harmonia consigo mesmo e com o universo. Pois, a presença de Deus impulsiona o ser humano a participar consciente e livremente na exploração da Vida que representa a mesma aventura cosmoteândrica da Realidade. A partir da abertura consciente para essa Presença a pessoa não espera passivamente. Ela espera tomando parte no advento de um mundo mais justo.

Logo, nesse encontro de profundidade não há uma separação entre o amor a Deus e o amor ao próximo. O Evangelho é uma mensagem de serviço e amor ao próximo (Mt 10,40), e o amor a Deus e o amor ao próximo são um só amor (1Jo 3,16). Dessa forma, faz-se necessário o compromisso com toda a criação, na responsabilidade por cuidar e preservar toda a natureza, na comunhão com o sofrimento e a dor de todos os povos até que lhes sejam restituídos a dignidade de filhos de Deus e um justo desenvolvimento econômico e social.

Portanto, essa atitude, longe de ser algo contingente no cristianismo, é uma consequência fundamental de uma fé autêntica, não somente pela gratidão a Deus que tudo criou, mas porque somos constitutivamente parte de toda a criação, e só estaremos em paz quando com ela estivermos em harmonia. $\mathrm{Ou}$ seja, essa experiência exige uma integração com toda a Realidade, com todo o cosmos, não somente com a natureza "viva", mas com toda a realidade que nos cerca, estando atentos tanto ao clamor da terra como ao clamor dos pobres.

Por esse motivo, a ecosofia, "sabedoria da Terra", apresentada por Panikkar, torna-se importante para a contribuição de uma relação harmoniosa de todos os seres humanos com a natureza. Como pudemos ver, será preciso uma metanóia, uma mudança radical de atitude que leve a reconciliação real entre o ser humano e a natureza, pois: "enquanto o homem e o mundo permanecerem inimigos, enquanto insistirmos em relacioná-los apenas como senhor e escravo, enquanto não se perceberem como constituintes, mundo e homem, nenhuma solução será encontrada. Nenhuma solução dualista pode ser sustentada". ${ }^{72}$

De tal modo, propomos uma mudança de atitude que deva ir além de uma visão redutora da Realidade, por meio de uma espiritualidade humanizadora e integral, e, porque não dizer, cosmoteândrica. Por se tratar de uma experiência que pressuponha todo o ser, ou seja, em viver de tal modo reconciliados com o que realmente somos, a partir do profundo encontro com Deus, abertos

72 PANIKKAR, R., La nueva inocencia, p. 40. 
aos demais e ao mundo em uma comunhão harmônica. Pois a boa nova do Evangelho é promessa de libertação e plenitude para toda a criação (Ef 1,10), e viver essa promessa é a missão do cristão.

Por fim, vislumbra-se, com a Exortação Apostólica Querida Amazônia, Pós-Sínodo Especial da Amazônia, a mudança na forma de agir das lideranças políticas no Brasil e no mundo, no comportamento de todas as pessoas, e um sopro do Espírito Santo dentro da Igreja. Uma vez que a glória do homem, imagem de Deus, consiste em levar a criação a uma reconciliação com Deus e a uma harmonia consigo mesma. Portanto, teremos uma oportunidade para a escuta e o diálogo com todas as realidades que diferenciam o território Pan-Amazônico em sua diversidade de povos, culturas e etnias, por causa da própria coerência que constitui a madura espiritualidade cristã.

\section{Referências bibliográficas}

ABUMALHAM, M. Presentación. 'Ilu - Revista de Ciencias de las Religiones, Anejo VI, p. 7-26, 2001.

BÍBLIA de Jerusalém. Nova ed. rev. e ampl. 2. impr. São Paulo: Paulus, 2003.

CASTRO, R. G. Redimindo Masculinidades: representações e significados de masculinidades e violência na perspectiva de uma teologia pastoral Amazônica. Rio de Janeiro, 2018. 258p. Tese. Faculdade de Teologia, Pontifícia Universidade Católica do Rio de Janeiro. Disponível em: < https://www. maxwell.vrac.puc-rio.br/34264/34264.PDF>. Acesso em: 28 fev. 2020.

CELAM. Conclusões de Santo Domingo. São Paulo: Paulinas, 1992.

CONCÍLIO VATICANO II. Constituição pastoral Gaudium et Spes. Petrópolis: Vozes, 1969.

DE LA PEÑA, J. L. Teología de la Criación. Santander: Sal Terrae, 1986.

FRANCISCO, PP. Carta Encíclica Laudato Si'. São Paulo: Paulinas, 2015.

FRANCISCO, PP. Exortação Apostólica Evangelii Gaudium. Brasília: CNBB, 2013.

FRANCISCO, PP. Exortação Apostólica Querida Amazônia. Brasília: CNBB, 2020.

MOLTMANN, J. Dios en la criación: Doctrina ecológica de la creación. Salamanca: Sígueme, 1997. 
MÜLLER, G. Dogmática. Teoría y práctica de la teologia. Barcelona: Herber, 1998.

PACHECO, A. S. En el corazón de la Amazonía: identidades, saberes e religiosidades no Regime das Águas Marajoaras. São Paulo, 2009. 353p. Tese. Faculdade de História, Pontifícia Universidade Católica de São Paulo.

PANIKKAR, R. Anima mundi-vita hominis-spiritus Dei. Alcuni aspetti di uma spiritualità cosmoteandrica. L'Atrapagina: Città di Castello, 1990. v.I.

PANIKKAR, R. Ecosofía. Para una espiritualidad de la tierra. Madrid: San Pablo, 1994.

PANIKKAR, R. De la mistica. Experiencia plena de la Vida. Barcelona: Editorial Herber, 2005.

PANIKKAR, R. Der Mensch ein trinitarisches Mysterium. In: PANIKKAR, R.; STROLZ, W. (Eds.). Die Verantwortung des Menschen für eine bewohnbare. Welt im Christentum, Hinduismus und Buddhismus. Freiburg: Herder, 1985. p. 147-190.

PANIKKAR, R. El espíritu de la política. Homo politicus. Barcelona: Península, 1999.

PANIKKAR, R. El mundanal silencio. Barcelona: Martínez Roca, 1999.

PANIKKAR, R. Experiencia de Dios. Madrid: PPC, 1994.

PANIKKAR, R. Humanismo y cruz. Madrid: Rialp, 1963.

PANIKKAR, R. La intuición cosmoteándrica. Las tres dimensiones de la realidad. Madrid: Editora Trotta, 1999.

PANIKKAR, R. La nueva inocencia. Pamplona: Verbo Divino, 1999.

PANIKKAR, R. La Trindad. Una experiencia humana primordial. Siruela: Madrid, 1998.

PANIKKAR, R. Misterio y revelación. Madrid: Marova, 1971.

PANIKKAR, R. Mito, fe y hermenéutica. Barcelona: Herber, 2007.

PANIKKAR, R. Paz y desarme cultural. Santander: Sal Terrae, 1993.

RAHNER, K. Curso fundamental da fé. Introdução ao cristianismo. São Paulo: Paulinas, 1989.

RUEDA, J. L. M. Ecosofia: otra manera de comprender y vivir la relación hombre-mundo. Cuestiones Teológicas, v.37, n.87, p. 119-144, 2010. 
RUEDA, J. L. M. La antropología de Raimon Panikkar y su contribución a la antropología teológica cristiana. Bogotá: Facultad de Teología, Pontificia Universidad Javeriana, 2010. (Coleccion Monografias y Tesis, 3).

SATTLER, D.; SCHNEIDER, T. Doutrina da Criação. In: SCHNEIDER, T. (Org.). Manual de dogmática. Petrópolis: Vozes, 2000. p. 114-215. v.1.

Francilaide de Queiroz Ronsi Doutora em Teologia Sistemática pela Pontifícia Universidade Católica do Rio de Janeiro Docente do Departamento de Teologia da Pontifícia Universidade Católica do Rio de Janeiro Rio de Janeiro / RJ - Brasil E-mail: francilaideronsi@hotmail.com

Recebido em: 02/03/2020 Aprovado em: 24/03/2020 